\title{
Goltz against cerebral localization: Methodology and experimental practices
}

\author{
J.P. Gamboa \\ Department of History and Philosophy of Science, University of Pittsburgh, 1101 Cathedral of Learning 4200 Fifth Avenue, Pittsburgh PA, 15260, USA
}

\section{A R T I C L E I N F O}

\section{Keywords:}

Friedrich Goltz

Cerebral localization

German physiology

Exploratory experimentation

\begin{abstract}
A B S T R A C T
In the late 19th century, physiologists such as David Ferrier, Eduard Hitzig, and Hermann Munk argued that cerebral brain functions are localized in discrete structures. By the early 20th century, this became the dominant position. However, another prominent physiologist, Friedrich Goltz, rejected theories of cerebral localization and argued against these physiologists until his death in 1902. I argue in this paper that previous historical accounts have failed to comprehend why Goltz rejected cerebral localization. I show that Goltz adhered to a falsificationist methodology, and I reconstruct how he designed his experiments and weighted different kinds of evidence. I then draw on the exploratory experimentation literature from recent philosophy of science to trace one root of the debate to differences in how the German localizers designed their experiments and reasoned about evidence. While Goltz designed his experiments to test hypotheses about the functions of predetermined cerebral structures, the localizers explored new functions and structures in the process of constructing new theories. I argue that the localizers relied on untested background conjectures to justify their inferences about functional organization. These background conjectures collapsed a distinction between phenomena they produced direct evidence for (localized symptoms) and what they reached conclusions about (localized functions). When citing this paper, please use the full journal title Studies in History and Philosophy of Biological and Biomedical Sciences.
\end{abstract}

\section{Introduction}

Despite Franz Joseph Gall's efforts to promote phrenology across several European countries, his theory of localized brain functions fell into disrepute by the mid-19th century (Young, 1990). Gall's observational methods received severe criticism at the hands of Jean Pierre Flourens who stressed the importance of experimentation. In the first half of the 19th century, Flourens was the first scientist to systematically lesion animal brains in order to study the functional architecture of the brain (Riese \& Hoff, 1951). By comparing the behavior of animals pre- and post-operation, Flourens concluded that the cerebrum is functionally homogeneous. In other words, each part contributes equally to the physiological functions of the organism. This view remained widespread and faced no serious challenges until Paul Broca presented the case of aphasia in 1861 (Tizard, 1959). Broca's fascinating case reinvigorated research on localization of brain functions. Between 1861 and the end of the century, the topic was fiercely debated (Finger, 1994). In Volume I of The Principles of Psychology, William James (1890/1950) remarked that "the quarrel is very acrimonious; indeed the subject of localization of functions in the brain seems to have a peculiar effect on the temper of those who cultivate it experimentally" (p. 46). By the end of the century, however, the debate simmered down and a consensus was reached: the brain is composed of discrete areas with specific psychological or physiological functions (Harrington, 2009; Star, 1989). In this sense, cerebral functions were considered experimentally localizable. ${ }^{1}$

The scientific study of cerebral localization in the late 19th century can be divided into three main branches: neuroanatomy, clinical research, and physiology (Hagner, 1994). This division is a historical convenience that does not reflect sharp boundaries. However, it captures three broad ways in which cerebral functions were investigated. Neuroanatomists used various staining and sectioning techniques to base cerebral functions in structurally differentiated areas of the brain. ${ }^{2}$ A notable figure here is Theodore Meynert. Because he advocated functional localization as early as the 1860 s, Meynert has been considered the German arch-localizationist (Hakosalo, 2006; Whitaker \& Etlinger, 1993). Physicians such as Broca and Carl Wernicke localized cerebral functions by examining human patients in clinics and linking

\footnotetext{
E-mail address: jog122@pitt.edu.

${ }^{1}$ My formulation of the position is intentionally narrow in order to capture the dominant view that is my focus. This formulation is neutral on functional localization regarding peripheral nerves and differences between large brain structures, though those have also been historically significant issues (Chirimuuta, ms.).

${ }^{2}$ For an excellent analysis of this research and the influence of staining and sectioning techniques on theories of localization, see Hakosalo (2006). Hagner (1994) also provides a good but briefer discussion.
} 
their symptoms to brain lesions examined post-mortem. Of course, the correlations they determined were limited to whatever lesions their patients happened to suffer from. By contrast, physiologists in laboratories targeted cerebral areas of interest by performing invasive procedures on animals.

Two kinds of techniques were available to physiologists investigating cerebral functions. The first was experimental ablation, the technique pioneered by Flourens. As lesion experiments proliferated in the late 19th century, the results were sometimes used in dramatic fashion at conferences in which experimenters presented their injured animals to the audience. For example, David Ferrier (1881) showcased his apparently hemiplegic and deaf monkeys at the International Medical Congress in London. The second technique was electrical stimulation of the brain, and it was first demonstrated by Gustav Fritsch and Eduard Hitzig in 1870. In their paper, they described experiments in which they produced specific bodily movements by stimulating local areas of the brain in both awake and anesthetized dogs (Fritsch \& Hitzig, 1870). This groundbreaking discovery overturned the longstanding belief that the brain cannot be excited (Hagner, 2012; Young, 1990). Although Broca's work in the 1860s revived the topic of cerebral localization, it did not receive much attention by German scientists during this decade (Hagner, 2012; Harrington, 1990). Fritsch and Hitzig's discovery in 1870 triggered a proliferation of German research on cerebral localization. ${ }^{3}$

This paper focuses on Friedrich Goltz, the most famous German antilocalizer who rejected cerebral localization until his death in 1902. Throughout the final quarter of the 19th century, Goltz engaged in a spirited debate with Hitzig and Hermann Munk, who were the most ardent German proponents of localization theories (Pauly, 1987). Although these localizers disagreed on significant issues, they both defended cerebral localization against Goltz's criticisms. While Hitzig is remembered for discovering cortical excitability and localizing motor functions, Munk is best known for localizing vision in the occipital lobes, which are still considered the seat of visual cortex (Finger, 1994).

Several historians have pointed out that Goltz's experimental ablations were imprecise compared to those of the localizers, and they have suggested that Goltz's anti-localization was based on his inferior experimental standards (Brazier, 1988; Finger, 1994; Walker, 1957b). Others have more charitably discussed some of his objections to localization theories (Pauly, 1983, 1987; Verplaetse, 2009). I will argue that previous historical accounts inadequately explain Goltz's resistance to cerebral localization by overlooking his broader methodological convictions. I will show how Goltz's unusually imprecise and macroscale ablations were intentional, and how they fit within his falsificationist philosophy of science. Goltz designed his experiments to test theoretical predictions, and his unconventional methods reflected the kinds of predictions he was testing. He attributed little epistemic value to confirming evidence and based his conclusions on failed predictions. Goltz believed that failed predictions refuted localization theories by providing definite grounds for inferring that functions and their supposed local structures were not lawfully connected. His commitment to a falsificationist approach also clarifies why he was unimpressed by confirming evidence produced by the localizers.

After placing Goltz's experimental methods and designs within the context of his broader scientific methodology, I will identify a significant difference in the experimental designs of the localizers. While Goltz designed his experiments to test hypotheses about the functions of predetermined cerebral structures, the localizers explored new functions and structures in the process of constructing new theories. Drawing on the exploratory experimentation literature from recent philosophy of science, I then argue that the localizers relied on untested background conjectures to justify their inferences about functional

\footnotetext{
${ }^{3}$ For an in-depth examination of the context and impact of their discovery, see Hagner (2012).
}

organization. These background conjectures collapsed a distinction between phenomena they produced direct evidence for (localized symptoms) and what they reached conclusions about (localized functions). By failing to make the distinction, the localizers inferred that each cerebral area normally has the function that is lost once the area is ablated. Analogously, they reasoned that each area is the functional center for the muscles that contract upon electrical stimulation of the area. Altogether, my analysis traces one root of the debate to specific differences in how the rivals designed their experiments and reasoned about evidence.

\section{The German localization debate and its background}

\subsection{A new physico-chemical foundation}

The rise of the physico-chemical approach to physiology around 1850 is an essential backdrop for understanding German localization research in the final quarter of the century. The movement was led by the "organic physicists" Karl Ludwig, Hermann von Helmholtz, Ernst von Brücke, and Emil du Bois-Reymond who rebelled against their "teleomechanist" teachers. ${ }^{4}$ They rejected vitalism, an early stage of the teleomechanist tradition which postulated a life force unique to living matter (Lenoir, 1982/2012). In his eulogy for Ludwig, Adolf Fick (1903) succinctly captured the organic physicists' alternative model of explanation: “... a biological phenomenon [Lebenserscheinung] can only be regarded as explained if it has been proven that it is the result of the material parts of the living organism interacting according to the laws which also govern those same parts outside of living systems" (p. 767). ${ }^{5}$ Believing that physiology would eventually dissolve into physics and chemistry, the organic physicists were committed to investigating all biological functions, including psychological ones, with the methods of natural science (du Bois-Reymond, 1848). It should be emphasized, however, that they were not committed to any metaphysical reduction of the mind. Indeed, Helmholtz (1910, p. 432) criticized materialism as metaphysical speculation, and du Bois-Reymond (1872, p. 17) famously claimed that consciousness is irreducible to material conditions and ultimately unexplainable by them.

Physiology rapidly expanded under the leadership of the organic physicists. In 1847 Ludwig invented the kymograph, a self-recording device which he used to study blood circulation. His widely used instrument was perceived as a symbol of the new era in physiology, and it inspired the development of many new instruments for recording and graphing physiological processes (de Chadarevian, 1993). By the early 1860s most German universities had created chairs for physiology which were separate from anatomy (Ben-David, 1960). ${ }^{6}$

Goltz, Hitzig, and Munk all trained in the 1850s and 1860s as the physico-chemical approach gained momentum, though prior to the opening of some of the major physiological institutes. For example, Ludwig's exemplary institute opened in Leipzig in 1869 (Lenoir, 1988), and du Bois-Reymond's Berlin Physiological Institute was completed in

\footnotetext{
${ }^{4}$ The "teleomechanism" research program was identified by Timothy Lenoir (1982/2012) in an important historical study that distinguishes it from the Naturphilosophie that dominated German investigations of biological phenomena in the late 18 th and early 19 th centuries. Influenced by Kant's teleology, the teleomechanists pursued mechanical investigations of life but maintained that organisms have purposive organization.

${ }^{5}$ All translations from German into English are my own except the quotes from (Vogt, 1846) (footnote 8) and Lange (1881) (footnote 16).

${ }^{6}$ Pauly (1987) argues that medical reform was the main impetus for the emergence of physiology as an independent discipline. On his account, medical reformers persuasively argued that medicine needed to be based on experimental physiology, and this helped justify the creation of physiology as an independent subject in German universities. Further institutional data on German physiology in the 19th century can be found in Zloczower (1981). Turner, Kerwin, and Woolwine (1984) provide a summary of this work.
} 
1877 (Otis, 2007). The two localizers were trained in Berlin by du BoisReymond and Rudolph Virchow among others (Breathnach, 1992; Gerabek, 1997). Goltz attended lectures by Helmholtz at the Königsberg Universität where he studied medicine and natural science (Ewald, 1903).

The German physiologists of the localization debate shared several core commitments with their mentors. They agreed that psychological functions should be studied with the methods of natural science, and they also aimed at discovering laws of nature (Goltz, 1881b, p. 159; Hitzig, 1904, p. 46; Munk, 1909, pp. 228, 308). Importantly, both of these commitments which shaped the debate were shared by various other groups as well. The psychiatrist Wilhelm Griesinger proclaimed in 1845 that mental diseases are brain diseases, and his reductive psychiatric program spread across German-speaking countries in the following decades (Guenther, 2015, p. 19). The scientific materialist and politician Karl Vogt boldly claimed in 1846 that "every natural scientist who thinks with any degree of consistency at all will, I think, come to the view that all those capacities that we understand by the phrase psychic activities (Seelenthätigkeiten) are but functions of the brain substance ..." (Vogt, 1846, quoted in Gregory, 1977, p. 64). ${ }^{7}$ Major works on scientific materialism were published in the 1850s, and its proponents further argued that all events are governed by natural laws, so the proper task of natural science is to discover such laws. More support for a law-governed model of explanation came from academic philosophers who did not practice natural science but were inspired by Kant. ${ }^{8}$ The "golden age" of Neo-Kantian philosophy began in the 1860 s and continued throughout the localization debate in the final quarter of the century (Beiser, 2014). From this very brief sampling of the intellectual landscape in the mid-19th century, it is clear that some important points of common ground in the localization debate were parts of much broader, interdisciplinary trends in German research.

\subsection{Objections and rebuttals}

The three physiologists disagreed about how functions are organized, and that was the crux of the debate. However, they agreed that physiological and psychological functions are organized in nervous tissue. As Pauly (1987, p. 17) points out, the pre-existing organization of the adult organism was a guiding assumption of most physiologists, including the organic physicists of the previous generation. Hitzig and Munk defended competing theories which individuated functions differently and thereby organized the brain into different functional centers. ${ }^{9}$ Goltz agreed with both that not all areas of the brain are functionally equivalent (Goltz, 1884, p. 450), but he denied that there are any tightly circumscribed functional centers. The localization doctrine at stake for Goltz was the view that all brain functions are sorted into structurally discrete, tight areas. Hitzig and Munk advocated such theories of brain organization, so they were direct targets. But this was certainly not the only kind of theory that fell under the banner of localization. The "arch-localizationist" Meynert believed that higher intellectual functions lack functional centers and depend on the whole forebrain (Guenther, 2015; Hakosalo, 2006). Sigmund Exner referred to his own theory as moderate localization ("gemäßigten Lokalisationismus"), but he thought complex functions depend on many structural

\footnotetext{
${ }^{7}$ Gregory's book provides a detailed examination of German scientific materialism in the 19th century.

${ }^{8}$ In his Metaphysical Foundations of Natural Science Kant argued that natural science is genuine only to the extent that it describes nature mathematically, and he took Newtonian physics as his model of explanation (Gregory, 2015; Patton, 2015; Kant, 1786/1922). Helmholtz is an example of a practicing natural scientist who was also important in the development of Neo-Kantian philosophy (Edgar, 2018).

${ }^{9}$ Specific points of disagreement are discussed in Hitzig (1904) part two chapter 3 and Munk (1909) chapter 12. Munk's sharp tone indicates how bitter their dispute was.
}

centers (Hagner, 1994). Accordingly, Goltz's dispute with Hitzig and Munk is best interpreted as a conflict over a specific, albeit common conception of cerebral localization. Unfortunately, Goltz did not spell out his own theory, so it is unclear how he envisioned functional organization beyond his rejection of tightly organized centers.

Goltz critiqued the research of the localizers in many ways during his decades-long polemic. I will describe just two main criticisms here. First, Goltz rejected all evidence from electrical stimulation experiments on the grounds that they left unclear precisely how far the electrical current spread (Goltz, 1881a). He took this uncertainty to block any credible inferences about the functions of stimulated areas. Goltz was not alone in his skepticism. When Fritsch and Hitzig initially published their discovery, Goltz's worry about controlling electrical current was a common concern among physiologists (Munk, 1890, p. 3). However, other physiologists like Ferrier and Munk began performing ablation and stimulation experiments in tandem, whereas Goltz maintained his distrust of electrical stimulation for the rest of his career.

Second, Goltz criticized localizers for failing to base their conclusions on dysfunctions which were permanent and exceptionless across cases (e.g., Goltz, 1881b, p. 34; 1884, p. 467; 1888, p. 445). He referred to such dysfunctions as "Ausfallserscheinungen" (roughly, "phenomena of loss"). ${ }^{10}$ Goltz's concept became highly influential in shaping theoretical discussions of localization as it was adopted by both neurologists describing human patients (Guenther, 2015; Wernicke, 1877) and physiologists working with animals (Ferrier, 1881; Hitzig, 1904; Munk, 1890; von Monakow, 1902). In order to preserve the distinction, I retain Goltz's term and reserve "dysfunction" for temporary deficits. "Symptom" is used as a general term for any behavioral effects of an experiment.

Goltz thought that behavioral deficits could provide evidence for the functions of lesioned areas only if they were Ausfallserscheinungen. The phenomenon of animals recovering from ablation experiments was known in the localization debate as restitution or substitution of function. Whereas localizers sought explanations of recovery within the localization paradigm (Harrington, 1989, p. 264), Goltz considered recovery from dysfunctions a serious problem for any theory of localization. If the area that supposedly had the function $x$ was destroyed, how could the animal regain the capacity to $x$ ? Goltz argued that explanations given by localizers (e.g. other brain areas taking on new functions) unwittingly gave up the doctrine of localization (Goltz, 1881b, p. 107).

He further argued that dysfunctions were due to temporary side effects of operations such as inhibition (Goltz, 1881b, p. 39; 1884, p. 455). If the loss of some function $x$ was due to side effects on various areas not directly damaged by an operation, it would be mistaken to infer that the targeted area had the function $x$. Based on his own experimental results, Goltz provided evidence for recovery or retention of functions after the destruction of supposed functional centers. He also reported the same symptoms in many cases despite ablating different cerebral areas. This is a different objection which I will examine more closely in section 5 .

Localizers in dialogue with Goltz responded to his objections in various ways, notably in how they explained recovery of functions (Goltz, 1881b, p. 107). However, both Hitzig (1904, p. 124) and Munk (1890, p. 77) explicitly rejected Goltz's demand to base their theories on Ausfallserscheinungen to the exclusion of temporary dysfunctions. They also agreed that Goltz's methods were unsuitable for investigating localization. In particular, they considered his experimental ablations too large and imprecise to test functionally discrete areas. As Hitzig put it at the Hughlings Jackson Lecture delivered to the Neurological Society of London, "the methods that Goltz at that time applied were; however,

\footnotetext{
${ }^{10}$ His exact definition is in Goltz (1884, p. 457), and it is a corrective to his informal use of the term in Goltz (1881b).
} 
clearly not suited to investigate the qualities of fixed localities of the cerebrum, in so far as these methods injured large parts of it ..." (Hitzig, 1900, p. 559). ${ }^{11}$ Similarly, in a lecture delivered to the Physiological Society of Berlin in 1877, Munk asserted, "Goltz's experiments likely show, in general, that after severe ablation of the cerebrum, certain important losses of functions remain permanently. But in particular, they do not and cannot teach anything about whether and which functions belong to the individual parts of the cerebrum" (Munk, 1890, p. 9). Whereas localizers typically lesioned minute regions within gross anatomical structures, Goltz consistently lesioned his animals at a far larger scale, sometimes excising entire lobes and hemispheres.

\section{Historical narratives and sources}

Why did Goltz persistently use such radically different experimental methods despite decades of criticism from most other physiologists? This is the historical puzzle motivating my analysis. Goltz was acutely aware of the finer-grained lesion experiments performed by localizers, and he discussed the details of their experiments throughout his own published work (e.g. Goltz, 1881b, p. 104; 1884, p. 466; 1888, p. 423). Nevertheless, he refrained from performing local lesions and insisted that his experimental results were irreconcilable with functional localization. One might surmise that Goltz was just a crude or careless experimenter. This interpretation is at odds with Goltz's prestige among his contemporaries. Indeed, Ferrier praised his character as a trustworthy observer (Ferrier, 1881, p. 228), and Hitzig insisted "I have always valued and recognised in the highest degree Goltz's services in the field of the physiology of the central nervous system" (Hitzig, 1900, p. 558). Although he is remembered for his steadfast rejection of cerebral localization, Goltz made many contributions to the study of reflexes (Goltz, 1869), the vestibular system (Goltz, 1870), and the circulatory system (Goltz \& Gaule, 1878). ${ }^{12} \mathrm{He}$ also performed the first successful decerebration experiment on a dog, demonstrating the unexpected capacities of a so-called higher mammal that lacked cerebral hemispheres (Goltz, 1892). Given his successful career and prominent status, Goltz's reliance on unconventional experimental practices is worth examining more closely. Yet it is left unexplained by previous histories.

Many historical descriptions of cerebral localization in the 19th century only briefly discuss Goltz, Hitzig, or Munk because they focus on French and British research (Star, 1989; Young, 1990), or their scopes are much broader (Harrington, 1989; Rothschuh, \& Risse, 1973; Swazey, 1970; Tizard, 1959; Walker, 1957a). For example, Rothschuh's History of Physiology is a valuable resource, but it ranges from antiquity to the 20th century. According to one narrative in some of the broad overviews, Goltz was simply wrong about the facts of cerebral localization, and he misinterpreted his results as contradicting localization theories because he lacked sufficient experimental control (Brazier, 1988; Finger, 1994, 2004). Several journal articles, especially those written by scientists, rehearse this narrative and romanticize the episode as a triumph of cerebral localization (Fishman, 1995; Morabito, 2017; Tyler \& Malessa, 2000; Walker, 1957b). Katja Guenther's Localization and Its Discontents stands out as a thorough and nuanced study of localization in 19th century German research. However, her aim is to trace the common roots of neurology and psychoanalysis, so she concentrates on physicians like Meynert and Wernicke. Historians who discuss the three physiologists with some depth and grounding in the original sources include Hagner (1994, 2012), Harrington (2009), Pauly (1983, 1987), and Verplaetse (2009). ${ }^{13}$

\footnotetext{
${ }^{11}$ He raised the same objection much earlier in chapter 10 of his book, which was originally published in 1876 (Hitzig, 1904).

${ }^{12}$ A full list of his publications on these and other topics is in Ewald (1903).

${ }^{13}$ Chapter 1 of Pauly (1987) and chapter 3 of Verplaetse (2009) are perhaps the best introductions to the debate between Goltz, Hitzig, and Munk. Pauly's
}

What all the previous historical studies have in common is that they limit discussion of Goltz to his experimental methods and theoretical objections to localization. My proposal is that grasping the rationale behind Goltz's unusual experimental practices provides a deeper understanding of his rejection of localization than the ones outlined above. This in turn delivers a deeper understanding of his conflict with Hitzig and Munk.

The following analysis synthesizes Goltz's methodological remarks spread throughout decades of his publications in order to elucidate how he conceived of his research program. ${ }^{14}$ Goltz was a diligent experimentalist and did not systematically develop a philosophy of science. However, he was very explicit in his writings about his methodological considerations. Far from being mere reports of his protocols and observations, Goltz's corpus flows seamlessly between reporting and personal reflection, including reflection on how one should reason from experimental results. The personal documents he left behind are kept at kept at the Halle-Wittenberg Universität in Germany and at Archives départementales du Bas-Rhin in France. Unfortunately, they are mostly bureaucratic or financial so they do not give insight into his relationships with previous mentors or how he developed his scientific methodology. The best biographic resource on Goltz is the over sixty page eulogy written by his student J. Richard Ewald who succeeded Goltz as chair of physiology at Strasbourg. Ewald (1903, p. 6) stressed Goltz's autodidactic nature in the development of his methods, but this should be interpreted with a grain of salt. Given the limited available sources, my exposition of Goltz's methodology is based directly on his publications. I begin with an overview of Goltz's experimental procedures and then examine the aims of his experiments and how he weighted different kinds of evidence. The analysis provides a basis for drawing out how Goltz's experimental designs and patterns of reasoning differed from those of Hitzig and Munk.

\section{Goltz's experimental techniques}

Goltz left Halle in 1872 to become chair of physiology and create his own institute at the Straßburg Universität (Ewald, 1903). In 1875 he began to concentrate his research on the topic of cerebral localization. With the exception of one rhesus macaque, all of his experiments for the remainder of his career were performed on dogs (Goltz, 1899).

Goltz's ablation methods can be divided into two phases: washing and cutting. In the early phase spanning from 1875 to 1878 , he ablated his animals by drilling holes into their skulls and washing out brain matter with a water jet. Goltz chose this method because he was familiar with the technique from his previous experience dissecting frog nervous systems, and because he assumed that this was the most effective way to keep animals alive by reducing bleeding (Goltz, 1881b, p. $3 ; 1892$, p. 570). During this phase, he initially ablated a single cerebral hemisphere in each animal. He then progressed to reporting observations from animals with both hemispheres ablated. The animals underwent up to four separate operations to progressively lesion their brains over the course of several months. Hardly any data were quantified, and it is impossible to determine what exactly Goltz ablated because he did not perform autopsies. Goltz was especially vague about how he experimented on the single hemisphere subjects. For instance, here is one typical description of an experiment from 1875:

On four different occasions, a quantity of brain mass from the left side was washed out from a powerful young dog. (Goltz, 1881b, p. 12).

Goltz was a bit more explicit about the double hemisphere ablation

\section{(footnote continued)}

chapter provides excellent contextualization, and Verplaetse's chapter offers the most detailed description of Goltz's experimental methods.

${ }^{14}$ All sources are the original texts. Only snippets of Goltz's work have been translated into English, and these are scattered across various sources (e.g. Lashley (1929) and von Bonin (1960). 


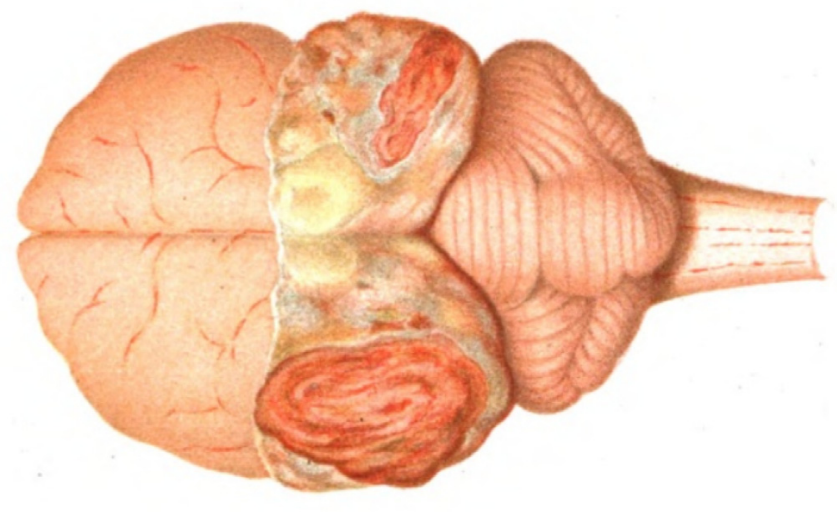

Fig. 1. From Goltz (1881b, p. 181) courtesy of the Internet Archive.

experiments, stating that he typically drilled in the area of the planum temporale (Goltz, 1881b, p. 45). However, he asserted "I never aimed to drill symmetrical holes on both sides of the skull. Therefore, the wounds in the brain couldn't possibly be perfectly symmetrical on both sides" (Goltz, 1881b, p. 72).

Goltz's early ablation experiments were undeniably imprecise compared to those of his peers. If one contrasts his experiments with those of Hitzig (1904) and Ferrier (1876) which were initially published earlier or in the same year, the differences in precision are striking. Both Hitzig and Ferrier named and diagrammed exactly which areas they lesioned, and they performed autopsies to verify these claims. Given such stark differences, it is unsurprising that localizers criticized Goltz's early work as too crude.

In 1879, Goltz abandoned the water jet in favor of various sharp instruments such as knives and scissors. During this cutting phase, Goltz focused on removing different combinations of large structures. From the dorsal view, Goltz divided the cerebrum into four quadrants and extirpated different combinations of the quadrants. In Fig. 1, for example, the two posterior quadrants are ablated.

$\mathrm{He}$ also removed various combinations of the four cerebral lobes, culminating in the extirpation of the entire cerebrum. Goltz claimed that he switched to cutting instruments so that he could remove these large sections as precisely as possible (Goltz, 1884, p. 453). Moreover, work from this period onward included autopsies, bodily measurements of the dogs, weights of extirpated matter, and in some cases photographs of his subjects at various stages. Despite these adjustments, Goltz still refrained from lesioning specific areas within gross anatomical structures. Although these experiments were more precise in their excisions, they were still limited to large areas differentiated by major gyri and sulci. Because the emerging consensus in the physiological community was that functions are localized in much smaller areas, experiments from Goltz's cutting phase were likewise rejected.

\section{Goltz's experimental designs}

Localizers clearly thought that researching cerebral localization required local interventions. Hitzig expressed this shared attitude by claiming, "if we wish to make experiments in localization, it is-however much Goltz may have said or may say against it—a simple demand of logic that we either bring stimulus to bear or cause lesion locally ..." (Hitzig, 1900, p. 558, original emphasis). By contrast, Goltz wrote, "it seems to me that the better way would be first to determine from the rough cases whether bigger portions of the brain show deviant functioning, and only later to study the particulars" (Goltz, 1881b, p. 101). From his perspective, not only were macro-scale lesions appropriate, localizers had gotten things backwards by beginning their experiments at the local scale. To some extent, this particular disagreement might have been rooted in a clash of intuitions. However, Goltz's intuition that it seems better to start with the rough cases can at best help to understand why he didn't choose local lesions as his starting point. It cannot explain why he thought macro-scale ablations were appropriate in the first place. In order to make sense of the latter, this section examines more closely what Goltz said about his experiments in each phase of his career. My aim is to place Goltz's experimental procedures within the context of his articulated experimental designs. This illuminates Goltz's motivations for experimenting in the odd manner described in the previous section.

One might suppose that Goltz switched techniques from washing to cutting because he came to see the force of his opponents' objection that the washing method was too crude. However, Goltz articulated the same defense of his water ablations in both phases of his career. Moreover, he agreed that by ablating in this way, he couldn't possibly remove the same brain areas across test subjects. Even within a single animal, he insisted that ablations to each cerebral hemisphere couldn't be symmetrical. But rather than seeing his imprecision as a problem, Goltz thought it produced a special kind of evidence against localization theories. He argued that if brains were partitioned into functionally discrete areas, then his washing method would eliminate different functional centers across cases (Goltz, 1881b, p. 102; 1888, p. 432). It follows from cerebral localization that “... the sum of symptoms that appear after each operation must be different, depending on whether this or that center was spared" (Goltz, 1881b, p. 102). Against this prediction, Goltz observed similar symptoms across many iterations of his experiments. In just one publication, for example, his discussion of double hemisphere ablation was based on the same experimental procedure (i.e. drilling and washing around the planum temporale) performed on 51 different dogs (Goltz, 1881b, p. 44). Moreover, as was typical for Goltz, these dogs were kept alive as long as possible to ensure that their symptoms were genuine Ausfallserscheinungen and not merely temporary. For Goltz, the consistency of his results despite the inconsistency of his water ablations was strong evidence against functional localization. Prima facie, it seems odd that Goltz deliberately lesioned his animals inconsistently with the water jet method, but his reasons are perfectly comprehensible given the predictions he aimed to test.

One overarching goal of Goltz's experiments during his cutting phase was to compare the effects of lesioning different large anatomical structures. Goltz remarked that:

if the cerebral matter of the cerebrum were homogeneous [gleichwertig] everywhere, one would expect that a dog that had lost all four quadrants would be distinct from one that possesses only two quadrants only in the degree of symptoms [Ausfallserscheinungen]. If by contrast cerebral functions were localized, then predictably, an animal which had lost both frontal quadrants would behave essentially different in the long run from one that had lost both posterior quadrants. (Goltz, 1881b, p. 133).

Goltz chose his experimental procedures in ways that would test such conflicting predictions.

In addition to comparing results from lesions in different large structures, Goltz tested predictions based on functions his opponents had supposedly localized. Pointing out that Ferrier, Hitzig, and Munk were all committed to the occipital lobes being essential for vision, Goltz removed both lobes in a dog (Goltz, 1884, p. 491). He then reported that this dog could usually avoid obstacles in its path. Goltz remarked that if the dog exhibited this capacity by relying on other senses, then it would move just as effectively blindfolded. Yet the dog resisted moving when blindfolded. As further evidence that it could see, Goltz placed sheets of white paper on the ground. Whereas his healthy dogs trampled over the papers when walking, the dog without occipital lobes avoided them like other, larger obstacles. Thus, Goltz concluded that the dog could see. Indeed, it could see very well. It simply could not recognize what it saw and use visual impressions for appropriate actions (Goltz, 1884, p. 492). This is just one of many experiments which tested a specific prediction of localization theories. 
Goltz's general strategy was to remove purported functional centers and then demonstrate that animals did not permanently lose the functions of those so-called centers. His most powerful cases against the localizers were his extirpations of entire cerebrums. According to localization theories, dogs without cerebrums lacked motor centers, hearing centers, visual centers, and so on. Yet Goltz reported evidence of all of their supposed functions (Goltz, 1892). He even kept one such dog alive for 18 months.

In both phases of his research, Goltz designed his experiments to test specific predictions both consistent and inconsistent with localization theories. Recognizing this point is necessary for understanding why he thought macro-scale ablations were appropriate. For Goltz, ablation at such a large scale made sense given the kinds of predictions that his experiments were designed to test (e.g. that an animal without occipital lobes will be unable to see).

\section{Goltz's scientific methodology}

Goltz followed a law-governed model of scientific explanation which cohered with the popular Neo-Kantian and scientific materialist traditions. As he put it, "I see the essential task of the physiologist as to investigate lawful connections between phenomena ..." (Goltz, 1881b, p. 159). On its own, this view hardly distinguished Goltz. As noted earlier, both Hitzig and Munk also aimed at discovering laws of nature. What was distinctive about Goltz was that he adhered to a specific way of designing experiments and reasoning about their results. In the previous section, I stressed that his experiments were designed to test theoretical predictions. Here I show that Goltz only attributed significant epistemic value to disconfirming experimental results. He believed that such evidence sufficed for falsifying a theory, and he designed his experiments with the primary aim of achieving this goal. I conclude by summarizing my proposed explanation for why Goltz conducted such unconventional experiments.

Goltz viewed falsifiability as a minimal condition on the acceptability of a theory. Another participant in the localization debate was the Italian physiologist Luigi Luciani. According to Luciani's (1886) theory, brains are organized into large functional centers which overlap one another. From Goltz's perspective, this theory had the advantage of accounting for various experimental results which were inconsistent with other localization theories. However, he remarked, "I confess that I can't warm up to this hypothesis of overgrown [functional] spheres because it is irrefutable [sich nicht widerlegen lässt]" (Goltz, 1888, pp. 434-435). Goltz's use of the verb widerlegen, which may be translated as "refute" or "disprove", is significant because it does not admit of degrees. To use Karl Popper's term, what Goltz stressed here was the importance of falsifiability. ${ }^{15}$

Goltz argued for the epistemic superiority of experimental results that disconfirm a theory. In the case of ablation experiments, he wrote.

... we are on safer ground for indisputable reasoning if we build our inferences from those phenomena which are not lost after the operation. If, for example, an animal after the removal of a specific brain area can still see, one may claim with absolute certainty that the removed brain area is not the only one that can support the sense of sight. One such positive observation is worth more than countless negative ones. (Goltz, 1884, p. 455).

Given this discrepancy in epistemic value, neglecting disconfirming evidence and focusing on results that confirm a theory would be a serious mistake. This is exactly what Goltz accused the localizers of in his essay "On the Modern Phrenology" (Goltz, 1885, p. 364).

For Goltz, the two kinds of evidence were unequal in epistemic

\footnotetext{
${ }^{15}$ Both Popper and Goltz used the root verb widerlegen and its morphological derivations. Although Popper (1935) more frequently used the words Falsifizierbarkeit and falsifizierbar (falsifiability/falsifiable), he actually used them interchangeably with Widerlegbarkeit and widerlegbar.
}

value because they supported different kinds of inferences. If an animal retained some function $x$ after an operation, one could infer that the ablated cerebral area was unnecessary for $x$. In other words, one could infer the absence of a law connecting the function and its alleged center, and this conclusion would be absolutely certain. Goltz believed that this was grounds for falsifying any theory localizing the function in that center. One failed prediction was all it took: "a single case in which a person or animal can still volitionally move all of its muscles despite severe loss of the motor zone would suffice to refute [widerlegen] the theory" (Goltz, 1884, p. 456). ${ }^{16}$

By contrast, if an animal lost the function $x$ after an operation, this would confirm theories localizing $x$ in the ablated area. On this basis, one could infer the presence of a law connecting the function and area. However, Goltz argued that such inferences were unreliable. Recall that he defined Ausfallserscheinungen as permanent and exceptionless dysfunctions. Only these dysfunctions qualified as evidence in favor of a lawful connection between a function and an area (Goltz, 1884). The central problem was that any dysfunction may appear to be an Ausfallserscheinung when in fact it was a contingent side effect:

If, after the removal of a brain area, one observes a paralysis of movement or a loss of sensation, one may never conclude that the removed brain area exclusively has the function that appears lost. The observed dysfunction may be caused by a side effect that was connected to the operation ... (Goltz, 1884, p. 455).

For each kind of operation, Goltz reported which dysfunctions seemed to be Ausfallserscheinungen. In this way, he drew inferences supported by the loss of functions. But he insisted that his results were not conclusive and he would not be surprised if future researchers discovered that his reported Ausfallserscheinungen were actually side effects (Goltz, 1884). One concrete way in which an experimenter might be deceived is by failing to observe an animal for a long enough period. For instance, in 1876 Goltz reported that dogs with damage to both cerebral hemispheres permanently lost the ability to use their front paws for actions like holding objects (Goltz, 1881b, p. 56). But after repeating the experiments in 1879 , he remarked that he had not observed the previous animals long enough, and dogs could in fact regain their abilities with their front paws (Goltz, 1881b, p. 100). He therefore rejected his initial judgment that the dysfunction was an Ausfallserscheinung.

We may now turn to a more detailed formulation of the puzzle with which I began. Why did Goltz relentlessly continue his imprecise water jet and macro-scale ablation experiments despite decades of criticism? Summing up the previous results, Goltz used these methods because they allowed him to test specific theoretical predictions. Although his own results occasionally confirmed predictions of localization theories, he attributed little epistemic value to them. At best, such evidence supported the defeasible conclusion that centers and functions were lawfully connected. Failed predictions, by contrast, allowed one to infer the absence of a law with absolute certainty. Goltz's law-governed model of explanation in natural science was prevalent among German researchers, and he believed that preserved functions falsified localization theories by demonstrating that functions and centers were not necessarily connected. His most compelling cases were the dogs in which he completely removed both cerebral hemispheres.

By overlooking his methodology, previous historical narratives inadequately characterize why Goltz rejected cerebral localization. Goltz's falsificationist methodology prescribed a specific way of

\footnotetext{
${ }^{16}$ Interestingly, this sentence very closely resembles a passage in The History of Materialism written by the Neo-Kantian philosopher Friedrich Lange. Discussing cases of intelligence retained despite damage to both frontal lobes, Lange claimed that "one such instance, however, is enough to overturn the whole system of phrenology" (Lange, 1881, p. 117). Although it is likely that Goltz read Lange's book given its popularity at the time (Beiser, 2014, ch. 9), Goltz did not explicitly refer to Lange anywhere in his corpus.
} 
experimenting and reasoning about evidence. The next section contrasts how the localizers designed their experiments and drew inferences from their experimental results.

\section{Hypothesis testing and exploratory experimentation}

Richard Burian (1997) and Friedrich Steinle (1997) introduced the term "exploratory experimentation" to the history and philosophy of science literature. Although they used the same term to capture distinct facets of scientific practice (Schickore, 2016), both authors challenged a theory-centric characterization of experimentation in science. Since the introduction of the term in the late 1990s, "exploratory experimentation" has been used as a conceptual tool for analyzing various historical and contemporary cases of experimental practices which are not "theory-driven" (Karaca, 2013; Schickore, 2016). Below I demonstrate that the experiments of Hitzig and Munk exemplified several core features of exploratory experimentation. A full analysis of their scientific methodologies is beyond the scope of this paper. However, recognizing the exploratory nature of their work is enough to distinguish their patterns of reasoning about experimental results from the one prescribed by Goltz's falsificationism. I argue that background conjectures linking their techniques to functional organization were essential for justifying the conclusions they inferred from their experimental results.

Exploratory experimentation is often characterized in contrast to hypothesis testing. According to Steinle's (1997) description of hypothesis testing, the "experiments are done with a well-formed theory in mind, from the very first idea, via the specific design and the execution, to the evaluation" (p. 69). He further notes that experimenters typically have specific expectations about the possible outcomes of their experiments. The description suits Goltz's approach. In some cases, Goltz's expected outcomes were open-ended (e.g. the dysfunctions between these animals will be different), and other times they were specific (e.g. these animals will become blind). But in all cases, the possible outcomes were derived from theories prior to experimentation, and Goltz grounded his theoretical conclusions in the outcomes that demonstrated the absence of a law.

Exploratory experimentation comes in several varieties (Elliott, 2007; Waters, 2007), and some of them were clearly not practiced by scientists in the 19th century. Franklin (2005), for example, describes a kind of exploratory experimentation in contemporary biology that depends on "wide" instruments which can rapidly measure variables or produce thousands of data points. Accordingly, the select few features of exploratory experimentation highlighted here are fairly general. First, a point of common ground in the exploratory experimentation literature is that such experiments are not designed to test hypotheses (Colaço, 2018). One reason why scientists might refrain from testing hypotheses is that they lack well-formed theories. Steinle $(1997,2002)$ argues that exploratory experimentation typically occurs when theories and concepts in the domain of inquiry are still nascent. He also stresses that systematic variation of experimental parameters is the key characteristic of exploratory experimentation (Steinle, 2002). Such variation allows experimenters to determine which parameters matter for the effects they produce, and it helps to establish empirical regularities. Rather than testing hypotheses, many exploratory experiments are designed to discover new entities and phenomena (Feest, 2012). The experiments of Hitzig and Munk shared all of the features of exploratory experimentation just described. To illustrate this, I examine just their most famous discoveries, though they both performed many electrical stimulation and ablation experiments.

As mentioned earlier, Fritsch and Hitzig's discovery of cortical excitability in 1870 profoundly shaped the trajectory of physiology. By progressively stimulating areas across the cerebrum, they determined which areas elicit muscular contractions, and they inferred the exact motor functions of those areas. Fig. 2 below is from their original paper. The proximity of the symbols immediately indicates the much finer scale of their interventions compared to Goltz's.

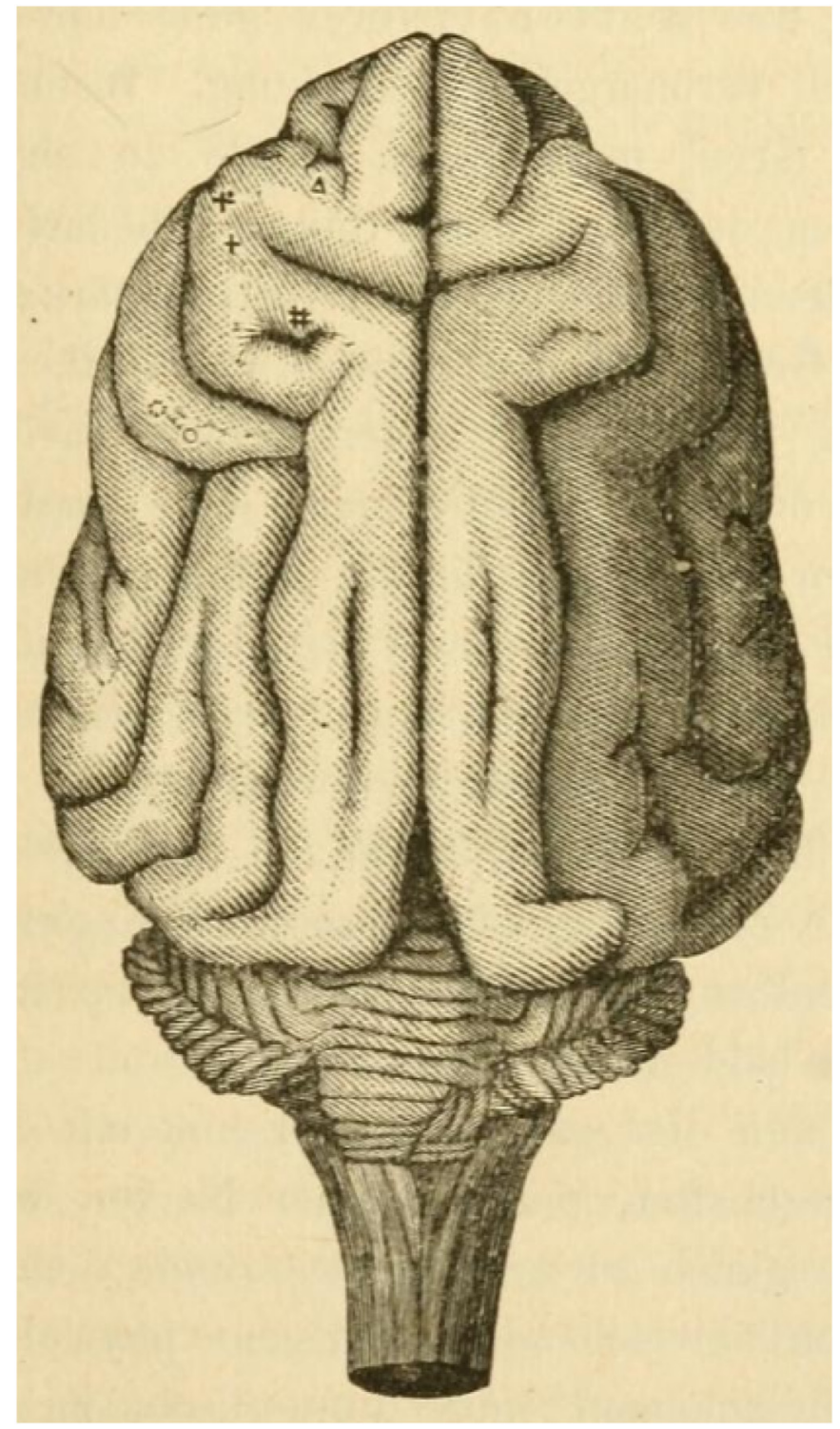

Fig. 2. From Fritsch and Hitzig (1870, p. 313) courtesy of Biodiversity Heritage Library.

They concluded, for example, that the area marked by the cross and dot is the center for the extensors and adductors of the front legs, whereas the area marked \# is the corresponding center for the posterior legs. As they pointed out, strengthening the current in the same area would increase the amount of muscles responding to the stimulation (Fritsch \& Hitzig, 1870, p. 311). They therefore isolated local centers by applying a weak current and determining the breadth of the area that produced the same movement in response to the stimulation. Importantly, neither structures nor functions were determined prior to experimentation. Instead, Fritsch and Hitzig discovered brand new centers within the known gross anatomy and inferred their functions. In accordance with Steinle's (2002) emphasis on systematic variation of experimental parameters, they tested different current strengths and progressively expanded their breadth of application. Moreover, they lacked a developed theory about functional organization because the equipotential conception of cortex was still dominant, and most German researchers at this point still avoided the topic of cerebral localization (Hagner, 2012; Harrington, 1990). Rather than testing theoretical predictions, Fritsch and Hitzig constructed a new theory of functional organization throughout the course of their stimulation experiments. 


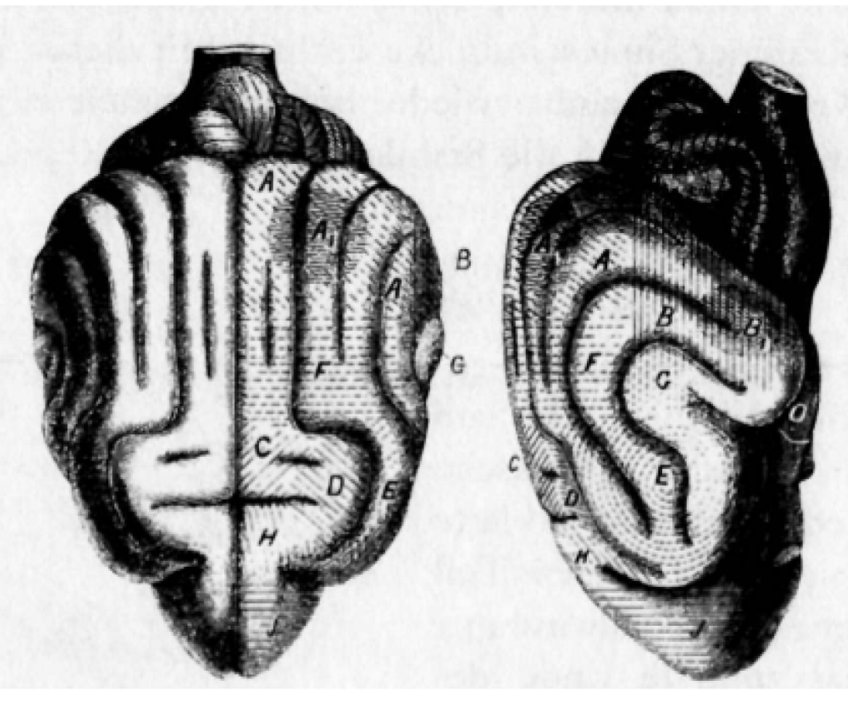

Fig. 3. From Munk (1890, p. 50) courtesy of HathiTrust.

Here is how Munk reported his discovery of the "seeing sphere":

... I proceeded completely systematically with the extirpation of the seeing sphere-always with different dogs-removing one time the inner part, another time the outer part, further the anterior half of the seeing sphere, then the posterior half. I extirpated in addition even smaller areas of the seeing sphere and strived to determine each time as exactly as possible the visual deficits. (Munk, 1890, p. 69).

By systematically ablating the occipital lobes (the entire region marked 'A' in Fig. 3) and observing deficits in his animals, Munk (1890) became convinced that each area of the lobes corresponds to a patch of vision. By lesioning just $A_{1}$, he also claimed to discover "psychic blindness". Unlike cortical blindness, animals with psychic blindness can see but fail to recognize what they see. Thus, Munk localized a cerebral basis for visual perception (A) and one for visual recognition $\left(A_{1}\right)$ within it. Just like Fritsch and Hitzig, Munk progressively searched for new functions and their structural bases by systematically varying the site of his intervention. He lesioned each site in order to observe what would happen, not to test hypotheses about what would happen. Although more theories of functional organization were available when Munk began his localization research in 1876, the debate was in full swing and physiologists were still developing new theories. Reflecting on his entrance into the debate, Munk attested:

... the localization of functions in the cerebrum was a physiological postulate for me. If localization had not yet sufficiently proved itself, it could only be because the ablation experiments, which must give the desired information, were not sufficiently varied with regard to site and size of the extirpation ... (Munk, 1890, p. 7).

By the time Munk began his research, he was already convinced that cerebral functions were localized. They simply needed to be charted on a map with more systematic investigation, and exploratory experimentation was an approach suited to this task.

If the major discoveries of the localizers did not involve hypothesis testing, what was the role of theory in their experiments? Several accounts in the philosophy of science literature emphasize that although exploratory experiments are not directed by fleshed out theories, they are nevertheless theory-laden in at least a weak sense (Karaca, 2013). Franklin (2005) attempts to resolve the apparent tension by distinguishing between "theoretical background" and "local theory". On her account, exploratory experiments are guided by some theoretical background comprised of the systematic knowledge available to experimenters about their field. But they are not directed by any theory about the behavior of the objects under investigation, which would be a local theory. Franklin's account prima facie fits the localizers because they were constructing new theories about functional organization at a time when Flourens' theory of functional homogeneity was still widely accepted. ${ }^{17}$ So it may seem that the localizers' experiments, at least initially, were not directed by local theories.

Colaço (2018), however, argues that the common conception of exploratory experimentation based on Franklin's distinction mischaracterizes the role of theory. Instead, he argues that beyond the more general theoretical background knowledge, exploratory experiments depend on claims about the relationship between the experimental technique and system under investigation. ${ }^{18}$ These claims are falsifiable, but they "... are needed to make inferences about characteristics of the target system based on an experiment's results" (p. 6). His point is that these claims are necessary for justifying the conclusions that researchers draw from their exploratory experiments. A closer look at the experiments of the localizers reveals that they did rely on such claims, albeit tacitly. Accordingly, I refer to them as background conjectures.

Fritsch and Hitzig (1870, p. 308) made explicit their intention to test the received view that the cerebrum cannot be excited. However, after they made their discovery of cortical excitability, they shifted to determining precisely which areas could elicit muscular contractions and which specific contractions corresponded to each area. At this point, the excitability of the cerebrum was no longer at issue. Fritsch and Hitzig began using their newfound technique to make inferences about the functional architecture of the brain. But how did they justify inferring from an experimental result (muscle $x$ contracts upon stimulating region $y$ ) to a functional conclusion (region $y$ has the function of contracting muscle $x$ )? Such an inference requires, as Colaço (2018) urges, a further claim which relates the experimental technique to the target of investigation. It requires a claim of the following form: cerebral areas have the motor function of producing the specific muscular contractions that result upon electrically stimulating them. Without such a claim, the inference from the experimental result fails. However, this sort of claim was not tested by Fritsch and Hitzig's experiments. It was taken for granted. It therefore served as a background conjecture which justified the conclusions they inferred. Moreover, this is precisely the sort of assumption that Goltz (1881a) challenged by arguing that it was unclear how far electrical currents spread in stimulation experiments. For Goltz, stimulating a specific area did not guarantee that it has the function of producing the observed effects because other functionally-relevant areas might have received current as well.

The analogous background conjecture in ablation experiments is easily discernible. When charting functional centers, localizers relied on the conjecture that each cerebral area has the function which is disrupted once the area is ablated. Only by accepting a background conjecture like this could Munk infer, for example, that the occipital lobes are the functional centers of vision by observing disrupted visual capacities upon lesioning those lobes. Again, this is precisely where Goltz targeted a major criticism. He argued that dysfunctions may be due to temporary side effects on areas which were not directly damaged by the operation (Goltz, 1881b, p. 39; 1884, p. 455). He even argued that such effects could be regularly connected with specific kinds of lesions because "strictly speaking, natural science knows no coincidences" (Goltz, 1884, p. 458). If dysfunctions were causally related to side effects on undamaged areas, this would undermine the inferences about functional organization that localizers drew from their ablation experiments.

Appreciating the justificatory role of background conjectures allows expanding on a point made by Stanley Finger. Finger (1994) claims that

\footnotetext{
${ }^{17}$ See Hagner (2012) for evidence that cerebral localization was not a serious alternative to equipotentiality theory for most German physiologists in the 1860s even after the interest generated by Broca in 1861 .

${ }^{18} \mathrm{He}$ also argues that these claims are best construed as "auxiliary hypotheses", but his insight can be applied without adopting this further terminological commitment.
} 
the debate over localization "... stemmed from how willing the combatants were to equate localization of symptoms with localization of function" (p. 56). ${ }^{19}$ While this was surely not the only source of the controversy, Finger captures an important point. Cerebral functions were neither directly observable nor localizable, but behavioral symptoms were. Therefore, localizers were compelled to support their theories by finding local cerebral bases for symptoms. My claim thus far has been that localizers justified their theoretical conclusions by tacitly accepting some form of the background conjectures given above. Applied to Finger's (1994) assessment of the debate, the background conjectures I've highlighted effectively collapsed the distinction between localization of symptoms and localization of functions. They clarify how localizers reasoned from their observations of muscular contractions and behavioral symptoms to maps of functional organization.

\section{Conclusion}

Previous historical studies of the localization debate in the late 19th century do not explain why Goltz ablated imprecisely in his early phase and continually experimented at a larger scale than his contemporaries. Indeed, many of them portray Goltz as a careless and stubborn scientist (Brazier, 1988; Finger, 1994, 2004; Morabito, 2017; Tyler \& Malessa, 2000). Against this simple narrative, I have argued that Goltz's unconventional experimental practices reflected a falsificationist methodology developed throughout a successful career as a widely respected physiologist. In their introduction to Rebels, Mavericks, and Heretics in Biology, Harman and Dietrich (2008) emphasize the value of focusing on historical individuals who challenged orthodoxy. In line with this perspective, my story paints a fuller picture of the localization debate by distinguishing how the rivals designed their experiments and how they inferred theoretical conclusions from experimental evidence.

One limitation of the present study is that it does not analyze the broader methodologies of the localizers, which is a project I leave for further work. Of particular interest is how they conceived of the relationship between evidence and laws of nature given that they rejected Goltz's demand to base their theories on Ausfallserscheinungen. However, it should not be taken for granted that Hitzig and Munk had a common methodology beyond the shared commitments outlined in section 2.1. Recent historiography emphasizes the turn in newer narratives toward capturing the heterogeneity of scientific practices in 19th century physiology (Kremer, 2009). In the same vein, this paper undermines early histories which describe a German "style" of physiology epitomized by the organic physicists (Mendelsohn, 1965; Temkin, 1946). Future work should likewise be wary of homogenizing the methodologies of various scientists simply because they landed on the same side of the localization debate.

The extent of exploratory experimentation in localization research is another issue that deserves more attention. In his original paper, Burian (1997) used the historical case of Jean Brachet to argue that “... exploratory work is a high art that can sustain long-term and productive research programs" (p. 29). Building on this idea, Waters (2007) argues that exploratory experimentation is often a feature of broader research programs, and programs can involve varying mixtures of exploratory experiments and hypothesis testing. Although I examined just the most famous discoveries of Hitzig and Munk, the laborious nature of 19th century vivisection suggests that exploration was not limited to a few experiments. Countless animals were sacrificed to achieve the systematic variation of lesions which Munk (1890, p. 7) explicitly described as essential for establishing cerebral localization. However, the breadth of exploratory experimentation is worth pursuing further

\footnotetext{
${ }^{19}$ The same distinction between the two types of localization was also made in the early 20th century by the American physician Morton Prince (1910). He criticized localization theories that failed to distinguish them.
}

because it provides a new lens for understanding localization research and the broader history of physiology.

The exploratory experimentation literature shows that many experiments in science are not theory-driven. Instead, when scientists lack well-formed theories, experiments are often conducted to discover new entities and phenomena. This paper demonstrates that 19th century physiology is no exception. Furthermore, it shows that philosophy can furnish conceptual tools and analyses for studying the history of science. In this case, philosophy helps to identify features of experimentation that tend to coalesce and to expose the background conjectures that scientists rely on even when they construct new theories by exploring empirical regularities.

\section{CRediT authorship contribution statement}

J.P. Gamboa: Writing - original draft.

\section{Declaration of competing interest}

None.

\section{Acknowledgements}

I am grateful to Mazviita Chirimuuta for guidance, comments, and thoughtful discussion throughout the process of researching and writing this paper. I also want to thank David Colaço for helpful suggestions and stimulating conversations about exploratory experimentation, Marina DiMarco and Jennifer Whyte for helpful comments on an early draft, and the two anonymous reviewers whose comments greatly improved the manuscript.

\section{References}

Beiser, F. C. (2014). The genesis of neo-kantianism, 1796-1880. Oxford University Press. Ben-David, J. (1960). Scientific productivity and academic organization in nineteenth century medicine. American Sociological Review, 25(6), 828-843. https://doi.org/10. $2307 / 2089980$.

du Bois-Reymond, E. (1848). Untersuchungen über thierische Elektricität. Berlin: G. Reimer. du Bois-Reymond, E. (1872). Über die Grenzen des Naturerkennens. Leipzig: Veit \& Comp. von Bonin, G. (1960). Some papers on the cerebral cortex (G. von Bonin, trans.): Thomas. Brazier, M. A. B. (1988). A history of neurophysiology in the 19th century. New York: Raven Press.

Breathnach, C. S. (1992). Eduard Hitzig, neurophysiologist and psychiatrist. History of Psychiatry, 3(11), 329-338. https://doi.org/10.1177/0957154x9200301104.

Burian, R. M. (1997). Exploratory experimentation and the role of histochemical techniques in the work of jean Brachet, 1938-1952. History \& Philosophy of the Life Sciences, 19(1), 27-45. Retrieved from www.jstor.org/stable/23332033.

de Chadarevian, S. (1993). Graphical method and discipline: Self-recording instruments in nineteenth-century physiology. Studies In History and Philosophy of Science Part A, 24(2), 267-291. https://doi.org/10.1016/0039-3681(93)90048-O.

Chirimuuta, M. (ms.). The historiography of the sciences of brain and nervous system. In M. R. Dietrich, M. Borrello, \& O. Harman (Eds.), Handbook of the historiography of biology (1 ed.): Springer International Publishing.

Colaço, D. (2018). Rethinking the role of theory in exploratory experimentation. Biology and Philosophy, 33(5-6), 38.

Edgar, S. (2018). Volume introduction - method, science and mathematics: Neo-kantianism and analytic philosophy. Journal for the History of Analytical Philosophy, 6(3), $1-10$.

Elliott, K. (2007). Varieties of exploratory experimentation in nanotoxicology. History \& Philosophy of the Life Sciences, 29(3), 313-336.

Ewald, J. R. (1903). Friedrich Goltz. Pflüger. Archiv für die Gesammte Physiologie des Menschen und der Thiere, 94(1-2), 1-64. https://doi.org/10.1007/bf01789423.

Feest, U. (2012). Exploratory experiments, concept formation, and theory construction in Psychology. In U. Feest, \& F. Steinle (Eds.). Scientific concepts and investigative practice (pp. 167-189). De Gruyter.

Ferrier, D. (1876). The functions of the brain. New York: G.P. Putnam's Sons.

Ferrier, D. (1881). Transactions of the international medical congress, seventh session, held in London. August 2d to 9th, 1881, Vol. III. London: J.W. Kolckmann.

Fick, A. (1903). Gesammelte schriften. Würzburg: Stahel'sche Verlags-Anstalt: Vol. 3.

Finger, S. (1994). Origins of neuroscience: A history of explorations into brain function. USA: Oxford University Press.

Finger, S. (2004). Minds behind the brain: A history of the pioneers and their discoveries. Oxford University Press.

Fishman, R. S. (1995). Brain wars: Passion and conflict in the localization of vision in the brain. Documenta Ophthalmologica, 89(1), 173-184. https://doi.org/10.1007/ 
BF01203410.

Franklin, L. R. (2005). Exploratory experiments. Philosophy of Science, 72(5), 888-899.

Fritsch, G., \& Hitzig, E. (1870). Über die elektrische Erregbarkeit des Grosshirns. Arch Anat Physiol Wissen 1870, Vol. 37, 300-332 Archiv für Anatomie, Physiologie und wissenschaftliche Medicin, 300-332.

Gerabek, W. E. (1997). Munk, Hermann. Neue deutsche biographie. Vol. 18. Neue deutsche biographie (pp. 595-). Berlin: Duncker \& Humblot.

Goltz, F. (1869). Beiträge zur Lehre von den Functionen der Nervencentren des frosches: A. Hirschwald.

Goltz, F. (1870). Ueber die physiologische Bedeutung der Bogengänge des Ohrlabyrinths. Archiv für die gesamte Physiologie des Menschen und der Tiere, 3(1), 172-192. https:// doi.org/10.1007/BF01855753.

Goltz, F. (1881a). Transactions of the international medical congress, seventh session, held in London, august $2 d$ to 9th, 1881. J.W. Kolckmann.

Goltz, F. (1881b). Ueber die Verrichtungen des grosshirns: Gesammelte abhandlungen: Strauss.

Goltz, F. (1884). Ueber die Verrichtungen des Grosshirns. Archiv für die gesamte Physiologie des Menschen und der Tiere, 34(1), 450-505. https://doi.org/10.1007/BF01612872.

Goltz, F. (1885). Ueber die moderne Phrenologie. Deutsche Rundschau, 45(12), 263-283 361-375.

Goltz, F. (1888). Ueber die Verrichtungen des Grosshirns: Sechste Abhandlung. Archiv für die gesamte Physiologie des Menschen und der Tiere, 42(1), 419-467. https://doi.org/ $10.1007 / \mathrm{bf01669366.}$

Goltz, F. (1892). Der Hund ohne Grosshirn: Siebente Abhandlung über Die Verrichtungen Des Grosshirns. Pflügers Archiv für die Gesamte Physiologie des Menschen und der Thiere, $51,570-614$.

Goltz, F. (1899). Beobachtungen an einem Affen mit verstümmeltem Grosshirn. Archiv für die gesamte Physiologie des Menschen und der Tiere, 76(7-8), 411-426.

Goltz, F., \& Gaule, J. (1878). Ueber die Druckverhältnisse im Innern des Herzens. Archiv für die gesamte Physiologie des Menschen und der Tiere, 17(1), 100-120. https://doi. org/10.1007/BF01703396.

Gregory, F. (1977). Scientific Materialism in Nineteenth Century Germany. Dordrecht, Holland: D. Reidel Publishing Company.

Gregory, F. (2015). Philosophy of science. In M. N. Forster, \& K. Gjesdal (Eds.). The oxford handbook of German philosophy in the nineteenth century. Oxford University Press.

Guenther, K. (2015). Localization and its Discontents: A genealogy of psychoanalysis and the neuro disciplines. University of Chicago Press.

Hagner, M. (1994). Lokalisation, Funktion, Cytoarchitektonik. Wege zur Modellierung des Gehirns. Objekte, Differenzen, Konjunkturen. Experimentalsysteme im historischen Kontext121-150.

Hagner, M. (2012). The electrical excitability of the brain: Toward the emergence of an experiment. Journal of the History of the Neurosciences, 21(3), 237-249.

Hakosalo, H. (2006). The brain under the knife: Serial sectioning and the development of late nineteenth-century neuroanatomy. Studies in History and Philosophy of Biological and Biomedical Sciences, 37(2), 172-202.

Harman, O., \& Dietrich, M. R. (2008). On Rebels, icons, and the value of dissent. In O. Harman, \& M. R. Dietrich (Eds.). Rebels, Mavericks, and Heretics in biology (pp. 1-19). New Haven, CT: Yale University Press.

Harrington, A. (1989). Medicine, mind, and the double brain: A study in nineteenth-century thought. Princeton University Press.

Harrington, A. (1990). In M. Teich, \& R. Porter (Eds.). The fin-de-siècle and its legacy. London: Cambridge University Press, 1990.

Harrington, A. (2009). The brain and the behavioral sciences. In J. V. Pickstone, \& P. J. Bowler (Vol. Eds.), The cambridge history of science: Volume 6: The modern biological and earth sciences: Vol. 6, (pp. 504-523). Cambridge: Cambridge University Press.

Helmholtz, H. (1910). Handbuch der physiologischen Optik (3rd ed.). Hamburg and Leipzig: Leopold Voss.

Hitzig, E. (1900). Hughlings Jackson and the cortical motor centres in the light of physiological research: Being the second Hughlings Jackson lecture delivered before the neurological society of London. British Medical Journal, 2(2083), 1564.

Hitzig, E. (1904). Physiologische und klinische untersuchungen über das gehirn: Gesammelte abhandlungen. Berlin: Hirschwald.

James, W. (1890/1950). The Principles of Psychology. Dover Publications.

Kant, I. (1786/1922). Metaphysische anfangsgründe der Naturwissenschaft. In E. Cassirer (Ed.). Immanuel kant's werke. Berlin: Bruno Cassirer.

Karaca, K. (2013). The strong and weak senses of theory-ladenness of experimentation: Theory-driven versus exploratory experiments in the history of high-energy particle physics. Science in Context, 26(1), 93-136.

Kremer, R. (2009). Physiology. In J. V. Pickstone, \& P. J. Bowler (Vol. Eds.), He cambridge history of science: Volume 6: The modern biological and earth sciences: . Vol. 6. T (pp. 342-366). Cambridge: Cambridge University Press.

Lange, F. A. (1881). History of materialism and criticism of its present importance (E. C. Thomas, trans, Vol. 3. Boston: Houghton, Mifflin, \& Co.

Lashley, K. S. (1929). Brain mechanisms and intelligence: A quantitative study of injuries to the brain. University of Chicago Press.

Lenoir, T. (1982/2012). The strategy of life: Teleology and mechanics in nineteenth century German biology, Vol. 13. Springer Netherlands.

Lenoir, T. (1988). Science for the clinic: Science policy and the formation of Carl Ludwig's institute in Leipzig. In W. Coleman, \& F. L. Holmes (Eds.). The investigative enterprise:
Experimental physiology in nineteenth-century medicine (pp. 139-178). Berkeley, CA, USA: University of California Press.

Luciani, L. (1886). Die Functions-Localisation auf der Grosshirnrinde, an Thierexperimenten und klinischen Fällen nachgewiesen. Leipzig: Denicke.

Mendelsohn, E. (1965). Physical models and physiological concepts: Explanation in nineteenth-century biology. The British Journal for the History of Science, 2(3), 201-219. https://doi.org/10.1017/S000708740000220X.

von Monakow, C. (1902). Über den gegenwärtigen Stand der Frage nach der Lokalisation im Grosshirn. Ergebnisse der Physiologie, 1(2), 534-665. https://doi.org/10.1007/ bf02320918.

Morabito, C. (2017). David ferrier's experimental localization of cerebral functions and the anti-vivisection debate. Nuncius, 32(1), 146-165.

Munk, H. (1890). Über die functionen der Grosshirnrinde: Gesammelte mittheilungen: Mit anmerkungen (2nd ed.). Berlin: August Hirschwald.

Munk, H. (1909). Über die functionen von Hirn und Rückenmark: Gesammelte mitteilungen. Berlin: Hirschwald.

Otis, L. (2007). Müller's Lab. Oxford University Press.

Patton, L. (2015). Methodology of the sciences. In M. Forster, \& K. Gjesdal (Eds.). The oxford handbook of German philosophy in the nineteenth century (pp. 594-606). Oxford University Press.

Pauly, P. J. (1983). The political structure of the brain: Cerebral localization in bismarckian Germany. International Journal of Neuroscience, 21(1-2), 145-149.

Pauly, P. J. (1987). Controlling life: Jacques Loeb and the engineering ideal in biology. New York: Oxford University Press.

Popper, K. R. (1935). Logik der Forschung: Zur Erkenntnistheorie der modernen Naturwissenschaft. Wien: Springer Verlag.

Prince, M. (1910). Cerebral localization from the point of view of function and symptoms: With special reference to von Monakow's theory of diaschisis. The Journal of Nervous and Mental Disease, 37(6), 337-354.

Riese, W., \& Hoff, E. C. (1951). A history of the doctrine of cerebral localization: Second part: Methods and main results. Journal of the History of Medicine and Allied Sciences, 439-470.

Rothschuh, K. E. (1973). History of physiology. G. B. Risse, Trans.R. E. Krieger Pub. Co.

Schickore, J. (2016). "Exploratory experimentation" as a probe into the relation between historiography and philosophy of science. Studies in History and Philosophy of Science, $55,20-26$.

Star, S. L. (1989). Regions of the mind: Brain research and the quest for scientific certainty. Stanford University Press.

Steinle, F. (1997). Entering new fields: Exploratory uses of experimentation. Philosophy of Science, 64, S65-S74. Retrieved from www.jstor.org/stable/188390.

Steinle, F. (2002). Experiments in history and philosophy of science. Perspectives on Science, 10(4), 408-432.

Swazey, J. P. (1970). Action propre and action commune: The localization of cerebral function. Journal of the History of Biology, 3(2), 213-234. Retrieved from www.jstor. org/stable/4330540.

Temkin, O. (1946). Materialism in French and German physiology of the early nineteenth century. Bulletin of the History of Medicine, Vol. 20(2), 322-327. Retrieved from www. jstor.org/stable/44441052.

Tizard, B. (1959). Theories of brain localization from Flourens to lashley. Medical History, 3(2), 132-145. https://doi.org/10.1017/S0025727300024418.

Turner, S., Kerwin, E., \& Woolwine, D. (1984). Careers and creativity in nineteenthcentury physiology: Zloczower redux. Isis, 75(3), 523-529. Retrieved from www. jstor.org/stable/232941.

Tyler, K. L., \& Malessa, R. (2000). The Goltz-Ferrier debates and the triumph of cerebral localizationalist theory. Neurology, 55(7), 1015-1024. https://doi.org/10.1212/wnl. 55.7.1015.

Verplaetse, J. (2009). Localizing the moral sense: Neuroscience and the search for the cerebral seat of morality, 1800-1930. Netherlands: Springer.

Vogt, C. (1846). Physiologische Briefe für Gebildete aller stände. Stuttgart and tübingen. J.G. Cotta.

Walker, A. E. (1957a). The development of the concept of cerebral localization in the nineteenth century. Bulletin of the History of Medicine, 31(2), 99-121. Retrieved from www.jstor.org/stable/44443969.

Walker, A. E. (1957b). Stimulation and ablation: Their role in the history of cerebral physiology. Journal of Neurophysiology, 20(4), 435-449.

Waters, C. K. (2007). The nature and context of exploratory experimentation: An introduction to three case studies of exploratory research. History \& Philosophy of the Life Sciences, 29(3), 275-284. Retrieved from www.jstor.org/stable/23334262.

Wernicke, C. (1877). Ein fall von Ponserkrankung. Archiv für Psychiatrie und Nervenkrankheiten, 7(3), 513-538.

Whitaker, H. A., \& Etlinger, S. C. (1993). Theodor Meynert's contribution to classical 19th century aphasia studies. Brain and Language, 45(4), 560-571. https://doi.org/10. 1006/brln.1993.1060.

Young, R. M. (1990). Mind, brain, and adaptation in the nineteenth century: Cerebral localization and its biological context from Gall to ferrier. Oxford University Press.

Zloczower, A. (1981). Career opportunities and the growth of scientific discovery in nineteenth century Germany. New York: Arno Press. 